14 Gray J, Bentovim A. Illness induction syndrome: paper I - a series of 41 children from 37 families identified at the Great Ormond Street NHS Trust. Child Abuse Neglect 1996; 20: 655-73.

15 Adshead G, Bluglass K. Attachment representations in mothers with abnormal illness behaviour by proxy. Br J Psychiatry 2005; 187: 328-33.

16 Ehrlich S, Pfeiffer E, Salbach H, Lenz K, Lehmkuhl U. Factitious disorder in children and adolescents: a retrospective study. Psychosomatics 2008; 49: 392-8.

17 Craig $\mathrm{TK}$, Cox AD, Klein $\mathrm{K}$. Intergenerational transmission of somatization behaviour: a study of chronic somatisers and their families. Psychol Med 2002; 32: 805-16.
18 Marshall T, Jones DPH, Ramchandani PG, Stein A, Bass C. Intergenerational transmission of health beliefs in somatoform disorders. Exploratory study Br J Psychiatry 2007; 191: 449-50.

19 Feldman $\mathrm{M}$, Rosenquist $\mathrm{P}$, Bond J. Concurrent factitious disorder and factitious disorder by proxy. Double jeopardy. Gen Hosp Psychiatry 1997; 19 24-8.

20 King B, Ford C. Pseudologia fantastica. Acta Psychiatr Scand 1988; 77: 1-6.

21 Adshead G, Bluglass $K$. A vicious circle: transgenerational attachment representations in a case of factitious illness by proxy. Attach Hum Dev 2001; 3: 77-95.

22 Berg B, Jones D. Outcome of psychiatric intervention in factitious illness by proxy (Munchausen's syndrome by proxy). Arch Dis Child 1999; 81: 465-72.

\title{
extra
}

\section{4:48 Psychosis (excerpt)}

\section{Sarah Kane}

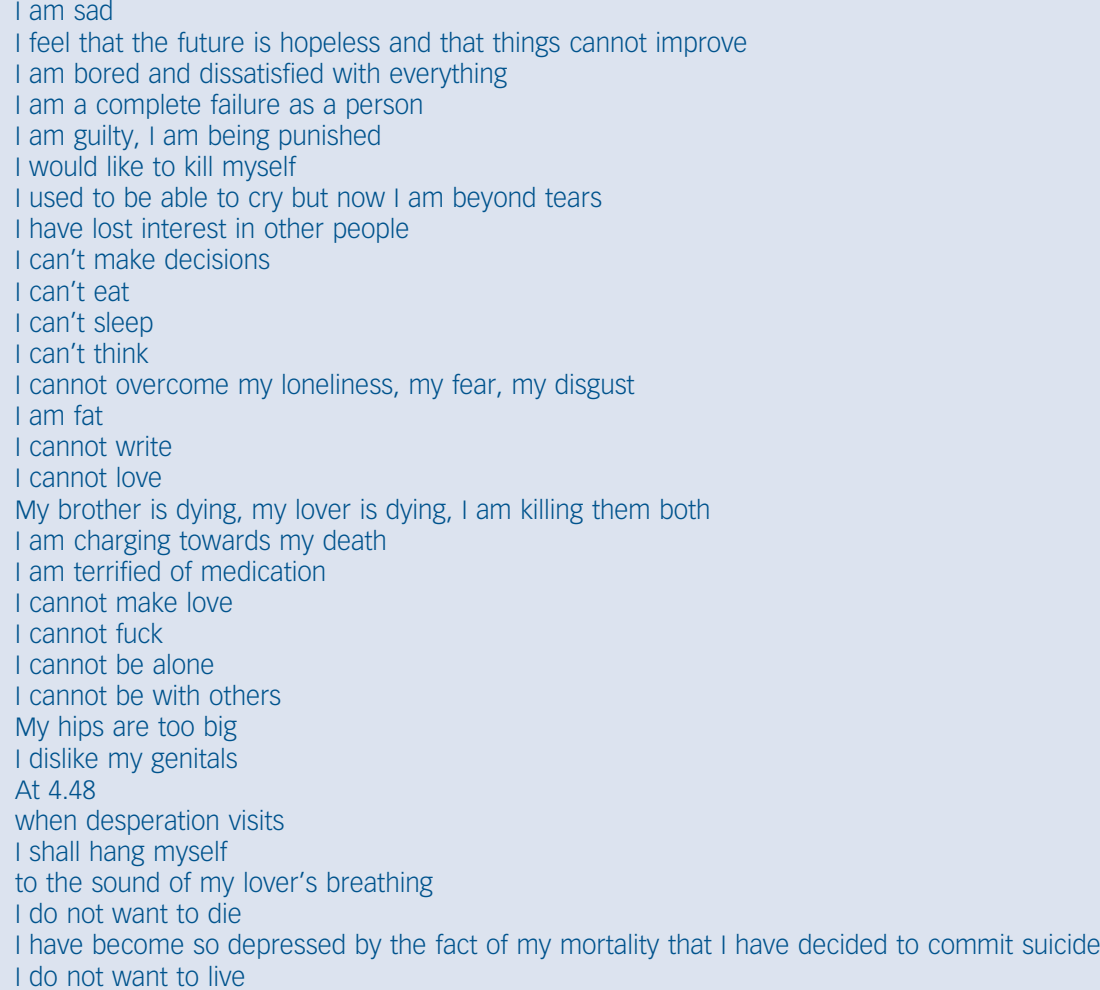

